\title{
La cláusula de terminación unilateral del contrato*
}

\author{
The Unilateral Termination Clause of the Contract
}

\author{
Jorge Oviedo-Albán ${ }^{\mathrm{a}}$ \\ Universidad de La Sabana, Colombia \\ jorge.oviedo@unisabana.edu.co \\ ORCID: http://orcid.org/0000-0003-2174-4765
}

DOI: https://doi.org/10.11144/javeriana.vj138.ctuc Redalyc: http://www.redalyc.org/articulo.oa id=82559799007

Fecha de recepción: 31 Julio 2018 Fecha de aprobación: 24 Agosto 2018 Fecha de publicación: 30 Mayo 2019

\section{Resumen:}

Este artículo tiene por objeto analizar el fundamento, valor y alcance de la cláusula de terminación unilateral del contrato en el Derecho privado colombiano, conforme a la cual se pacta entre los contratantes que cualquiera de ellos puede dar por terminado el contrato sin necesidad de alegar una justa causa. Luego de indagar por el fundamento y viabilidad jurídica de esta cláusula, sus límites, al igual que su posible configuración como abusiva y contraria a la buena fe, se concluye que si bien es posible admitir su viabilidad jurídica, esta cláusula encuentra límites y eventualmente puede ser declarada nula. Para la elaboración se ha empleado el método dogmático de investigación jurídica, que tiene en cuenta las disposiciones legales, la doctrina y la jurisprudencia, tanto sentencias de la Corte Suprema de Justicia, como del Consejo de Estado y laudos arbitrales.

Palabras clave: Contrato, terminación unilateral, cláusula abusiva.

\section{Abstract:}

The purpose of this article is to analyze the basis, value and scope of the unilateral termination clause of the contract in Colombian private law, according to which it is agreed between the contracting parties that any of them may terminate the contract without having to plead a just cause. After investigating the basis and legal viability of said clause, its limits, as well as its possible configuration as an abusive clause and contrary to good faith, it is concluded that although it is possible to admit its legal viability, this clause finds limits and may eventually be declared void. For the elaboration the dogmatic method of legal investigation has been used, taking into account the legal dispositions, the doctrine and jurisprudence, both judgments of the Supreme Court of Justice, as of the Council of State and arbitration awards.

Keywords: Contract, unilateral termination, abusive clause.

\section{Introducción}

La posibilidad de terminar o "revocar" voluntariamente un contrato por acuerdo de quienes consintieron en formarlo, encuentra fundamento en la autonomía de la voluntad de los contratantes, pues según este postulado las partes son libres para crear, modificar o extinguir las relaciones jurídicas convencionales ${ }^{1}$. Esto encuentra sustento además en el carácter de la intangibilidad del contrato, reconocido en el artículo 1602 del Código Civil, conforme al cual todo contrato legalmente celebrado es ley para los contratantes y no puede ser invalidado sino por mutuo consentimiento o causas legales ${ }^{2}$.

Tal acuerdo, como resulta obvio, debe cumplir los requisitos de existencia y validez de todos los actos jurídicos. Además de ello, valga recordar que el Código Civil enuncia en el artículo 1625 entre los modos de extinción de las obligaciones, el acuerdo entre los contratantes denominado también en la doctrina como mutuo disenso ${ }^{3}$. De esta manera, entonces, no les es permitido a los contratantes terminar de manera unilateral el contrato, dado que ello haría que este dejara de ser ley para las partes ${ }^{4}$. Pero, como se verá, ya sea

Notas de autor: 
por excepción legal o por prerrogativa contractualmente reservada para uno de los contratantes, se concede en ocasiones la facultad de hacerlo ${ }^{5}$.

Partiendo de lo anterior, este artículo versa sobre el interrogante acerca de la viabilidad y alcance en el Derecho privado colombiano de una cláusula de terminación unilateral del contrato, sobre todo en el evento en que sea predispuesta por una de las partes. Se busca sostener que si bien es posible admitir su viabilidad jurídica, esta cláusula encuentra límites y eventualmente puede ser calificada como abusiva y contraria a la buena $\mathrm{fe}^{6}$.

Para lograr el objetivo propuesto se indagará por el fundamento y viabilidad jurídica de la cláusula de terminación unilateral del contrato (I), como también el límite (II) y su posible configuración como cláusula abusiva además de sus consecuencias (III). Para su elaboración se han tenido en cuenta las disposiciones legales pertinentes, al igual que doctrina y jurisprudencia relevantes, tanto sentencias de la Corte Suprema de Justicia, como del Consejo de Estado y laudos arbitrales. El artículo termina con un cuerpo de conclusiones y relación de bibliografía empleada.

\section{Fundamento y viabilidad jurídica}

Como se indicó en la introducción, cabe reiterar que en principio la legislación colombiana parte del supuesto de que los contratos se terminan, entre otras causas, por acuerdo entre las partes, tal como lo establecen los artículos 1602 y 1625 del Código Civil. Ello no obsta para que el propio Código Civil (CC) y también el de Comercio (Co), en ocasiones admitan la posibilidad de terminación unilateral del contrato. Esto, independientemente de que usen diferentes vocablos como revocación, renuncia, desistimiento, etc.

7 . También cabe agregar la posibilidad consagrada en el artículo 47 de la Ley 1480 de 2011, que permite el retracto en todos los contratos para la venta de bienes y prestación de servicios mediante sistemas de financiación otorgada por el productor o proveedor, venta de tiempos compartidos o ventas que utilizan métodos no tradicionales o a distancia ${ }^{8}$.

En la doctrina española contemporánea, LUIS DÍEZ-PICAZO ha dicho que es posible admitir la terminación de una relación obligatoria por la voluntad de una de las partes, la cual puede tener su fundamento en la concreta atribución a uno o a ambos interesados, de la facultad de extinguir la relación, bien sea como consecuencia de una expresa disposición legal o en virtud de la concesión hecha a cualquiera de los contratantes por el negocio jurídico constitutivo de las obligaciones ${ }^{9}$. Entre los autores colombianos también hay voces favorables a esta posibilidad, como la de LUIS FELIPE BOTERO-Aristizábal, al destacar que en la legislación nacional no hay prohibición para incluir y ejercer esta facultad ${ }^{10}$. Igualmente en Chile, en la doctrina se ha contemplado tal posibilidad, como es el caso de RENÉ ABELIUK-MANASEVICH, quien además de referirse a los casos expresamente contemplados en la ley indica que la revocación unilateral del contrato puede ser pactada por las partes, concediendo este derecho a cualquiera de ellas para desvincularse del mismo, ya sea al cumplimiento de algún evento determinado, por su sola voluntad, o previo pago de una indemnización ${ }^{11}$.

El Código Civil italiano de 1942 contempla la posibilidad de receso o rescisión unilateral del contrato en el artículo $1373^{12}$. Conforme a esa norma, si a una de las partes se le hubiese atribuido la facultad de rescindir el contrato, esta podrá ser ejercitada mientras el mismo no haya tenido principio de ejecución, aunque en todo caso, como se prevé al final del artículo, queda a salvo cualquier pacto en contrario ${ }^{13}$. Si se tratare de un contrato de ejecución periódica o sucesiva, esta facultad también se puede ejercer posteriormente, pero no tendrá efecto en cuanto a las prestaciones ya ejecutadas o que se encuentren en curso de ejecución. De todas maneras, se ve como una facultad excepcional no susceptible de interpretación extensiva a otros contratos ${ }^{14}$. 
En el Derecho argentino, tal posibilidad también ha sido contemplada expresamente en el artículo 1077 del Código Civil y Comercial de la Nación de $2015^{15}$.

Cabe agregar que en algunos de los instrumentos que componen el "moderno derecho de los contratos", se consagra la posibilidad de terminar el acuerdo por cualquiera de las partes, en contratos a término indefinido. Así el artículo 5.1.8 de los Principios de Unidroit ${ }^{16}$. De manera similar, los artículos 6:109 de los Principios de Derecho Europeo de Contratos (PECL, y el artículo III-1:109(2 del DCFR ${ }^{17}$.

María Luisa Palazón-Garrido indica que no será necesaria la cláusula en los contratos sometidos a tales instrumentos, aunque de todas maneras vale la pena considerar la variable introducida por la misma autora, consistente en que en la cláusula se prevea una obligación de compensación por el ejercicio del desistimiento; esta resulta conveniente para garantizar la indemnidad del contratante que resulte perjudicado con la decisión de terminación unilateral del otro ${ }^{18}$. También cabe señalar que bajo el régimen de tales instrumentos la cláusula de terminación unilateral puede no ser necesaria para los contratos de larga duración, pero sí para aquellos que no lo sean. En este sentido, el numeral 1 del artículo III-1:109 DCFR dispone: "Los derechos, obligaciones o relaciones contractuales pueden modificarse o extinguirse mediante notificación por cualquiera de las partes si así se estipula en los términos que lo regulan".

En diversas ocasiones, la jurisprudencia colombiana ha admitido la posibilidad de pactar la terminación unilateral del contrato por cualquiera de las partes. Así lo señaló la Corte en un fallo de 1941, a propósito de un contrato en el que se le permitía a una compañía terminar el contrato si no se encontraba petróleo “... y demás hidrocarburos en cantidades explotables y de provecho comercial, o si en el curso de la explotación esos elementos disminuyeren hasta hacerla improductiva o se agotan, o si los títulos de los propietarios no resultan saneados, o si sobreviene otra causa que implique para la compañía inconveniente o perjuicio en la continuación del contrato..." ${ }^{19}$.

En esta decisión, la Corte precisó que esta cláusula no corresponde a la prohibición establecida en el artículo 1535 del Código Civil, conforme al cual "Son nulas las obligaciones contraídas bajo una condición potestativa que consista en la mera voluntad de la persona que se obliga”, sino más bien a lo que establece el inciso segundo de la misma norma, según el cual "Si la condición consiste en un hecho voluntario de cualquiera de las partes, valdrá” 20 .

De igual forma, en otro fallo la Corte reconoció la posibilidad de cualquiera de las partes de dar por terminado el contrato, bien sea en los casos en los que expresamente el legislador la consagra, o cuando la misma proviene del pacto entre los contratantes, tal como se indicó en Sentencia de la Corte Suprema de Justicia de 14 de diciembre de $2001^{21}$. La demanda se refirió a una indemnización por un siniestro cubierto mediante un contrato de seguro, cuyo pago solidario se requirió de parte de un grupo de aseguradoras. En primera instancia, se declaró probada la excepción de inexistencia del contrato de seguro, se absolvió a una de las demandadas y se condenó a otra de ellas. En apelación, se declaró probada la excepción de revocación unilateral del asegurado frente a lo cual se desestimó la pretensión interpuesta contra otra de las aseguradas y se condenó a la demandante a pagar costas. La Corte Suprema casó la sentencia y condenó a la aseguradora contra la cual se había desestimado la pretensión en apelación.

También en sentencia de 30 de agosto de 2011, además de hacer una detallada referencia a los casos en los que el legislador ha admitido la posibilidad de terminación unilateral del contrato, consideró viable pactar una cláusula que la prevea. El caso objeto de discusión se refirió a una demanda de declaración de responsabilidad civil extracontractual por incumplimiento de contratos de afiliación o vinculación de unos vehículos y en subsidio resolución. Esta pretensión se fundó en la terminación unilateral de los contratos que, según el demandante, se configuró como incumplimiento del acuerdo, además de ser contraria a la buena fe y la prórroga automática pactada al finalizar su duración mínima. En primera instancia se decretó la responsabilidad civil contractual de la demandada. En apelación se revocó la sentencia y la Corte Suprema no 
la casó. En las consideraciones, la Corte manifestó que la terminación unilateral del contrato está admitida en casos específicos en la ley y de todas formas, las partes la habían pactado ${ }^{22}$.

Sobre la cláusula que prevé la terminación unilateral, la Corte señaló:

En cuanto respecta al pacto de terminación unilateral del contrato cuando la ley, costumbre o los usos y prácticas negociales no la establecen, de antaño suele cuestionarse, ya por oponerse a la noción o fuerza normativa del contrato (artículos 1494, 1535, 1602 y 1603, Código Civil; 864 y 871, Código de Comercio), ora por invalidez e ilicitud al someterlo a la condición potestativa consistente en el simple arbitrio o mera voluntad de un contratante (artículo 1535, Código Civil), bien al no enunciarse dentro de las causas legales extintivas, formarse y terminar por acuerdo mutuo de las partes, nunca por decisión de una (artículo 1602, in fine, Código Civil), preverse en forma excepcional, exclusiva y circunscrita a los contratos estatales sin admitir analogía legis o iuris ni aplicación extensiva (artículos 14, 15, 16 y 17, Ley 80 de 1993), resultar abusiva en los restantes (artículo 133.2, Ley 142 de 1994) o, convertirse en mecanismo de \#justicia privada\#, derogatorio de la jurisdicción del Estado autorizada para terminar el contrato.

En estrictez, la terminación unilateral presupone la existencia, validez y eficacia del contrato, en nada contradice su noción, fuerza normativa, ni encarna condición potestativa.

El contrato a partir de su existencia genera efectos vinculantes para las partes, atadas u obligadas al cumplimiento, sea espontáneo, sea forzado, y fenece por decisión exclusiva de una porque la ley concede el derecho o se pacta accidentalia negotii, como las cláusulas resolutorias expresas, con o sin preaviso e, incluso, casos hay, donde la común negativa se ha tomado como dissensus o distrato o concluye en este (Cas. Civ. sentencia de 12 de marzo de 2004). El contrato existe ex ante, engendra efectos, termina ex post sin eficacia retroactiva y solo hacia el futuro. Además, cumplimiento y terminación son distintos. Aquel no queda al simple arbitrio o mera voluntad de una parte, la última se produce por decisión unilateral de una u otra sin afectar las obligaciones cumplidas.

La falta de enunciación expresa en el Código Civil dentro de los modos extintivos, no es escollo ni argumentación plausible para descartar la terminación unilateral, por cuanto como quedó sentado, la ley la consagra en numerosas hipótesis y contratos de derecho privado, sin concernir solo a los estatales. Inclusive, la figura existe en el derecho privado, antes de su plasmación en la contratación estatal, y no es extraña la locución, pues utiliza el vocablo \#terminación\# (artículo 870, C. de Co), \#dar por terminado el contrato\# (art. 973, C. de Co), justas causas \#para dar por terminado unilateralmente el contrato de agencia comercial\# (art. 1325, C. de Co).

Tampoco es admisible sostener prima facie, ante sí y por sí, su naturaleza abusiva, extender la presunción al respecto circunscrita a los contratos de servicios públicos bajo condiciones generales (artículo 133.2, Ley 142 de 1994), esta sí destierra la analogía legis, ajena a los paritarios y susceptible de desvanecerse, sin resultar lógica la supuesta configuración antelada de un abuso de derecho ulterior, el cual podrá presentarse al ejercerse en ciertas condiciones, o tenerla a priori como expresión abusiva de la libertad contractual, por contradecir las reglas de experiencia (Cas. Civ. sentencia de 14 de diciembre de 2001, exp. 6230).

En general, ante la ausencia de prohibición normativa expresa, es ineluctable concluir la validez de estas cláusulas, por obedecer a la libertad contractual de las partes, facultadas para celebrar el acto dispositivo y disponer su terminación, aún sin declaración judicial, previendo el derecho a aniquilarlo, lo cual no significa ni puede conducir en forma alguna a tomar justicia por mano propia, por cuanto toda controversia respecto de su eficacia o ejercicio, corresponde definirla a los jueces, como se explica más adelante.

Partiendo de la precedente premisa, la jurisprudencia reconoce validez a las cláusulas de terminación de los contratos bilaterales, onerosos, conmutativos y de ejecución sucesiva (Cas. Civ. sentencia de 3 de septiembre de 1941, LII, 1966, 36 y ss; 23 de febrero de 1961, XCIV, 549), y las relativas a \#[1]a condición resolutoria estipulada expresamente por los contratantes [que] resuelve de pleno derecho el contrato sin que se requiera declaración judicial. El artículo 1546 del C.C. se refiere a la condición resolutoria tácita, es decir a la que envuelve todo contrato bilateral, y no a la expresa, o sea a la que libremente hayan estipulado las partes\# (Cas. Civ. sentencia de 31 de mayo de 1892, VII, 243).

(..)

Desde otra perspectiva, la terminación unilateral, es realidad tendencial inocultable en la contratación, particularmente, en la internacional, electrónica y las relaciones comerciales, así como las de consumo, tanto cuanto más por la sensible evolución, secular transformación, dimensión y entendimiento actual de la autonomía privada en la dinámica del tráfico jurídico y los negocios ${ }^{23}$.

El Consejo de Estado de igual forma ha señalado que la facultad de terminar unilateralmente el contrato conforme a una cláusula que así lo disponga, es una estipulación "reconocida y con eficacia en materia de derecho", tal como se estableció en fallo de 2 de mayo de $2016^{24}$. El caso que motivó el pronunciamiento del Consejo de Estado, se refirió al recurso de anulación interpuesto por Centrales Eléctricas del Cauca 
S.A. E.S.P., CEDELCA, en contra del laudo de 4 de abril de 2014 dictado con ocasión de las controversias suscitadas entre dicha entidad (convocada) y la Compañía de Electricidad del Cauca S.A. E.S.P. (convocante). La decisión del Consejo de Estado declaró infundada la solicitud de anulación del laudo arbitral recurrido. El laudo referido versó a su turno sobre la pretensión planteada por la convocante en sentido de señalar que la terminación unilateral del contrato por la convocada alegando incumplimiento por parte de la convocante, no estaba fundada en una justa causa. El tribunal de arbitramento consideró que no se habían configurado en el caso concreto las causales para que la convocada terminara el contrato por justa causa y de manera anticipada y además que tal terminación había desconocido principios como la buena fe y la preservación de los contratos. En relación con la cláusula de terminación unilateral indicó:

Ciertamente el artículo 1602 del Código Civil prescribe que los contratos solo pueden invalidarse por causas legales o el mutuo acuerdo de las partes. En el mismo sentido, el artículo 1625 ibídem prescribe que la extinción de las obligaciones debe darse por la convención de los interesados o por las diez causales allí consagradas. Sin embargo, tal enumeración resulta insuficiente, pues el mismo Código reconoce causales adicionales en otras disposiciones, como la declaración unilateral de terminación, como sucede con el desahucio, la cesación, la renuncia o la revocación, que se encuentran reconocidas en artículos tales como el 2009, 2011,2056, 2189 y 2193. Otro tanto sucede con el desistimiento, que constituye una forma de terminación unilateral ante la insatisfacción de las expectativas del acreedor ${ }^{25}$.

No sobra insistir en que la cláusula de terminación unilateral del contrato no puede ser calificada como una condición meramente potestativa, que está prohibida por el artículo 1535 del Código Civil en los siguientes términos:

Son nulas las obligaciones contraídas bajo una condición potestativa que consista en la mera voluntad de la persona que se obliga.

Si la condición consiste en un hecho voluntario de cualquiera de las partes, valdrá.

En efecto, el asunto no consiste en que el cumplimiento de las obligaciones surgidas del contrato quede al mero arbitrio de las partes. Se trata de que el contrato pueda ser extinguido por decisión de cualquiera de las partes, independientemente de que cualquiera de ellas ostente la calidad exclusiva de deudor o acreedor, o de que de ambas calidades sean titulares todos los contratantes. Además de ello, las obligaciones que se hubieran ejecutado no son susceptibles de ser extinguidas, sino que el contrato se termina hacia futuro. En este sentido se pronunció un tribunal de arbitramento, al indicar:

\footnotetext{
No considera el Tribunal que la facultad de terminación pactada constituya una condición meramente potestativa (conditio si voluero), esto es aquella que consiste en la mera voluntad de la persona que se obliga (artículo 1535 del Código Civil), pues como fue convenida, dicha estipulación no tiene por objeto extinguir derecho u obligación por la mera voluntad del deudor, sino brindar a ambos contratantes la posibilidad de poner término al contrato en forma unilateral, sin afectar las obligaciones contraídas y ejecutadas al amparo del negocio jurídico, que devienen inalterables y consolidadas. Por consiguiente, la terminación unilateral del contrato solo produce efectos hacia el futuro (ex nunc) y no puede alterar o modificar obligaciones ya contraídas o ejecutadas ${ }^{26}$.
}

\section{Límites a las cláusulas de terminación unilateral del contrato}

A pesar de ser viable pactar una cláusula que permita a cualquiera de las partes terminar unilateralmente el contrato, según lo anotado en el punto anterior, esta posibilidad tiene límites que, como lo ha afirmado la Corte Suprema también en fallo anteriormente citado, son los que se derivan del abuso del derecho y, en particular, de la buena fe, por lo cual la misma podría resultar abusiva. Así se expresó la Corte en sentencia de 2011 ya citada:

$\mathrm{Al}$ respecto, la estipulación podrá contrariar una norma imperativa, resultar abusiva, comportar el ejercicio de posición dominante contractual, abuso del derecho, vulneración de la confianza legítima, el acto propio (venire contra factum proprium) o la buena fe, o incluso una conducta formalmente ajustada al ordenamiento jurídico o al contenido de la 
estipulación de terminación unilateral valorada en el marco fáctico concreto de circunstancias, puede devenir abusiva e ilegítima, o en las ad nutum, configurar ejercicio disfuncional, por ejemplo, para inferir intencionalmente un daño, aspectos que en función de la justicia, imponen cuidadoso examen del marco de circunstancias fáctico por los jueces dentro de su autonomía hermenéutica y la discreta valoración de los elementos de convicción.

El abuso del derecho, y en particular, la buena fe, son parámetros limitativos y correctores de la libertad contractual, y por ende, ostentan particular relevancia en estos aspectos.

La jurisprudencia, reconoce en precisas circunstancias que el ejercicio de la facultad de terminación unilateral, no configura de suyo un abuso de derecho (artículo 830, C. de Co), sin sentar una directriz general inflexible ni descartarlo a priori, por cuanto, podrá ser abusiva, y por regla general, en los casos legales o contractuales, la parte puede terminar el contrato con sujeción a la corrección, lealtad, buena fe y recto ejercicio de los derechos, pero en lo \#...contractual tiene cabida el abuso del derecho...\#, y puede \#...presentarse en la formación del contrato, en su ejecución, en su disolución y aín en el periodo postcontractual\# (LXXX, 656; Cas. Civ. sentencias de 6 de diciembre de 1899, XV, 8; sentencia de 6 julio de 1955, LXXX, 656; 11 de octubre de 1973, CXLVII, 82; 19 de octubre de 1994, exp. 3972), de donde, en armonía con el artículo 95 de la Constitución Política, según el cual, todas las personas están obligadas a \#[r]espetar los derechos ajenos y no abusar de los propios\#, deben \#entenderse las cláusulas convencionales o las regulaciones legales o constitucionales permisivas de la terminación unilateral del pacto respectivo, debido a que ellas no pueden interpretarse a distancia del postulado de que se viene hablando, como quiera que exigen ser observadas a través de su propio prisma, ante la posibilidad de que en ejercicio de esa facultad se incurra en violación del derecho ajeno; ello supone entonces que deben apreciarse bajo el entendido de que su actividad no puede ser causa de daño a quienes han contratado con el agente, salvo, claro está, que exista razón que lo justifique, como sucedería, verbi gratia, cuando el comportamiento del contratista, dada su falta de honradez o inteligencia, lo imponga\# (Cas. Civ. sentencia de $16 \mathrm{de}$ septiembre de 2010, exp. 11001-3103-027-2005-00590-01).

A esta directriz, se sujetan las prerrogativas ad nutum, ad libitum o a arbitrio, en cuyo ejercicio el titular no es ajeno \#al inexorable y plausible deber constitucional y legal de no abusar de sus derechos (arts. 95, 1 C.P.y 830 C.Co.), habida cuenta que el reconocimiento de una facultad o poder, de por si, no constituye salvoconducto o patente de corso para propiciar la arbitrariedad, so pena de la condigna indemnización de los perjuicios irrogados. Es por ello por lo que el abuso, en sí, trasciende al mero o a la simple volición\# (Cas. Civ. sentencia de 14 de diciembre de 2001, exp. 6230).

En consecuencia, todas las expresiones específicas de terminación unilateral del contrato, el ejercicio del derecho potestativo, incluso discrecional, se rigen por los principios de la buena fe, evitación de abuso del derecho y está sujeto a control judicial, lo cual suprime la justicia privada por mano propia. La buena fe y el abuso del derecho, constituyen límites al pacto y ejercicio de estas facultades ${ }^{27}$.

Así también lo ha señalado el Consejo de Estado:

...la autonomía privada de la voluntad permite que las partes puedan autorregular sus intereses, incluyendo las formas de terminación de sus vínculos, sin que por ello se concluya que existe un acto abusivo por alguna de ellas o que se esté desconociendo el equilibrio connatural de las partes, siempre que obren de buena fe al concluir sus relaciones ${ }^{28}$.

Adicionalmente, Ernesto Rengifo-Garcĺa ha afirmado en la doctrina colombiana, que el abuso del derecho constituye un límite a la facultad discrecional de las partes para terminar unilateral y anticipadamente aquellos negocios de duración soportados en la confianza ${ }^{29}$. De igual manera, el autor afirma que si la predisposición de la cláusula de terminación unilateral, o su ejercicio o aplicación resulta irrazonable, desproporcionado o contrario a la buena fe, así debe ser juzgado ${ }^{30}$.

En España, LUIS DÍEZ-PICAZO y ANTONIO GULLÓN se han pronunciado en cuanto a los límites de la decisión unilateral de ponerle fin a la relación obligatoria, indicando que esta debe ser recepticia y ejecutada de buena fe, lo cual además impone la existencia de un plazo de preaviso y la necesidad de prolongar la realización por el tiempo necesario para que la otra parte tome las medidas correspondientes ${ }^{31}$.

Díez-Picazo agrega que la violación de la buena fe en el ejercicio de la facultad de desistimiento no impide la extinción de la relación y crea únicamente un deber de resarcimiento de daños, concretado en el pago de las restituciones por el tiempo de preaviso que no se hubiere respetado ${ }^{32}$. De todas maneras, cabe agregar que, además del limitante de la buena fe para el ejercicio del derecho concedido a las partes por medio de esa cláusula, esta también encuentra como límite el que en sí misma pueda ser calificada como abusiva, según se verá, con las consecuencias que más adelante igualmente se indicarán. También en Italia, C. MASSIMO BIANCA afirma que el principio de buena fe implica que el poder de desistimiento unilateral se ejercite de 
tal manera que se salvaguarde el interés del otro contratante, si eso no exige un sacrificio apreciable ${ }^{33}$. En igual sentido se ha manifestado en la doctrina argentina ALEJANDRO Borda, a propósito de la posibilidad de terminación unilateral contemplada en el artículo 1077 del Código Civil y Comercial de la Nación ${ }^{34}$.

Además de lo enunciado, un límite que se reconoce igualmente al ejercicio de la cláusula de terminación unilateral del contrato es el consistente en el preaviso de parte del contratante que quiere abandonar la relación contractual. En efecto, en la doctrina, FERNANDO HINESTROSA indica que el "preaviso" es un requisito que debe cumplir la cláusula de terminación unilateral, salvo que se trate de circunstancias que lo autoricen de otra forma ${ }^{35}$. C. MASSIMO BIANCA también se pronuncia en relación con exigir un preaviso para la terminación unilateral, como manifestación de la buena fe, de tal manera que la importancia que la relación puede tener para el contratante y la dificultad en encontrar un reemplazo inmediato, pueden exigir que el desistimiento se comunique con un preaviso adecuado ${ }^{36}$.

Las excepciones en las que no se requiera tal preaviso, agrega Hinestrosa, estarían dadas en los eventos en que haya un motivo importante, o justa causa, un incumplimiento especialmente grave, la desaparición de una condición fundamental del contrato, o que las circunstancias permitan obrar incontinenti ${ }^{37}$.

\section{Configuración y alcance de la cláusula de terminación unilateral como eventualmente abusiva}

Aun cuando pueda asumirse - como se puede—, que la cláusula de terminación unilateral es válida al tener fundamento en la autonomía de la voluntad o excepcionalmente legal y que, por ende, el que la ejerce está empleando un derecho potestativo, corresponde analizar si puede inferirse que resulta abusiva al haber sido dispuesta por uno de los contratantes, sin haberla negociado o informado previamente al otro. Ahora, independientemente de que también en el caso concreto pudiera llegarse a reprochar a la otra parte el no ser lo suficientemente diligente para identificar la cláusula y, por ende, objetarla durante el proceso de negociación, resulta más reprochable la conducta del contratante predisponente que no hubiere cumplido con el deber precontractual de información considerado como manifestación del deber de obrar de buena fe consagrado en el artículo 863 del Código de Comercio, entendido a su vez como el obrar leal y correcto que se exige a las partes ${ }^{38}$.

Cabe agregar además que en este caso se dan las características que la jurisprudencia de casación civil ha exigido para que una cláusula sea calificada como abusiva. En efecto, la Corte Suprema, en sentencia de 2 de febrero de 2001, estableció:

se advierten como características arquetípicas de las cláusulas abusivas — primordialmente-: a) que su negociación no haya sido individual; b) que lesionen los requerimientos emergentes de la buena fe negocial — vale decir, que se quebrante este postulado rector desde una perspectiva objetiva: buena fe probidad o lealtad - , y c) que genere un desequilibrio significativo de cara a los derechos y las obligaciones que contraen las partes ${ }^{39}$.

Varios laudos arbitrales han calificado la cláusula de terminación unilateral como abusiva, como sucedió en el laudo arbitral de Adriana María Calderón-Palacio contra Cafesalud Medicina Prepagada S.A., de 15 de noviembre de $2002^{40}$. El caso se refirió a un contrato de prestación de servicios de digitación. Tiempo después de su celebración y estando en ejecución, la demandada notificó a la demandante la terminación del contrato. La parte convocante demandó que se decretara la terminación arbitraria del contrato, además de la inexistencia del parágrafo de la cláusula que permitía la terminación unilateral del mismo antes de su vencimiento y sin que mediara justificación. El Tribunal decidió que tal cláusula era abusiva y en sus consideraciones expresó que esta es la impuesta o dictada “...por la parte que detenta la posición fuerte o dominante y que por ello ostenta un preeminente poder de negociación, privilegia o favorece inequitativamente al predisponente en detrimento del adherente, lesionando con ello el normal equilibrio del 
contrato". En cuanto a la cláusula del contrato que permitía a la entidad dar por terminado el contrato, señaló que esta es válida en el supuesto en que se pacte la posibilidad de dar por terminado el contrato en eventos de incumplimiento, pero sí reprochó el parágrafo en que facultaba a la entidad a dar por terminado el negocio en cualquier tiempo y sin tener que aducir razón alguna ${ }^{41}$.

También en otro laudo arbitral se consideró que una cláusula que permita al predisponente dar por terminado el contrato en cualquier tiempo y, especialmente, sin necesidad de dar explicación, es abusiva ${ }^{42}$. En cuanto a la calificación como abusiva de una cláusula, el tribunal sostuvo:

En efecto, la circunstancia de que el contenido material de una estipulación sea válido, no excluye la posibilidad de que se configure una cláusula abusiva, puesto que, según se ha explicado, no es la transgresión a la ley imperativa, el orden público o las buenas costumbres, lo que torna abusiva una cláusula, sino la ventaja marcada que persigue, el notorio desequilibrio que genera, su irrazonabilidad y falta de justificación, así, en abstracto, el contenido material de la cláusula, individualmente considerado, no resulte censurable ${ }^{43}$.

En otro laudo arbitral, también se indicó que el ejercicio de la facultad de terminación unilateral por cualquiera de los contratantes no significa per se que se configure abuso del derecho, según lo que establece el artículo 830 del Código de Comercio, aunque bien es cierto que su ejercicio puede resultar abusivo. Así el tribunal afirmó:

El ejercicio de la facultad de terminación unilateral por parte de alguno de los contratantes no configura por sí mismo abuso del derecho en los términos del artículo 830 del Código de Comercio, aunque puede ocurrir el caso que dicha atribución se ejerza en detrimento de los derechos del otro contratante. Por consiguiente, el uso de este tipo de cláusulas o de potestades contractuales no puede hacerse en forma arbitraria o abusiva, caso en el cual, de llegar a causarse vulneración de los derechos del otro contratante, debe deducirse la responsabilidad por esa circunstancia $(. . .)^{44}$.

Otro caso se refirió a una demanda en la que se controvirtió una cláusula de terminación unilateral que había sido introducida en el texto del acuerdo modificatorio del contrato celebrado entre las partes, que permitía a cualquiera de ellas terminar el acuerdo previo aviso escrito al otro contratante con antelación mínima de 30 días hábiles para la finalización. El tribunal de arbitramento consideró que la cláusula era abusiva por la forma en que había sido dispuesta e insertada en el texto definitivo del documento que la contenía, sin haber cumplido con el deber precontractual de información derivado de la buena fe $\mathrm{f}^{45}$.

Ahora, en relación con el efecto y sanción que se genera para una cláusula abusiva, se ha sostenido que es la nulidad absoluta de la misma por violar una norma imperativa, como es el ordinal primero del artículo 95 de la Constitución Política, conforme al cual los ciudadanos deben respetar los derechos ajenos y no abusar de los propios ${ }^{46}$. Así se decidió en el caso Punto Celular Ltda. contra Comunicación Celular S.A. - Comcel ${ }^{47}$.

De igual forma se procedió en el tribunal de arbitramento en el caso de 3PL Logistic Solutions Colombia S.A.S. contra VIRBAC Colombia Ltda. En el laudo se decretó la nulidad absoluta de la misma por objeto ilícito, al considerar que resultaba violatoria del artículo 95 de la Constitución que impone como deber de la persona y del ciudadano "respetar los derechos ajenos y no abusar de los propios" ${ }^{48}$.

Adicionalmente, debe tenerse en cuenta que, al tratarse de una causal de nulidad absoluta, el juez o árbitro están facultados para decretarla de oficio según lo dispuesto en el artículo 1742 del Código Civil subrogado por el artículo 2 de la Ley 50 de 1936. Si bien es cierto que el Código de Comercio no señala si se requiere o no declaración judicial en torno a la nulidad absoluta o a la anulabilidad, debe tenerse en cuenta que en los aspectos que en ese Código no están especialmente regulados se aplican de forma directa las disposiciones del Código Civil, toda vez que así lo establece el artículo 822 del Código de Comercio ${ }^{49}$. Por esto, ante el aparente silencio del Código de Comercio, deben aplicarse los artículos 1742 y 1743 del Código Civil, en los cuales se establece que la nulidad, tanto absoluta como relativa (o, para efectos mercantiles, la anulabilidad), debe ser declarada por el juez ${ }^{50}$. 
Ahora, si la nulidad de la cláusula no afecta todo el contrato, se trata de una nulidad parcial en los términos del artículo 902 del Código de Comercio, de tal manera que es esta cláusula — y no las otras — la que será objeto de la declaración de nulidad. Este ha sido el criterio adoptado tanto en la doctrina, como en algunos laudos arbitrales, en el sentido de asumir que esta nulidad parcial es una manifestación del principio de conservación del contrato ${ }^{51}$. Por todo lo anterior y considerando que el artículo 1742 del Código Civil subrogado por el artículo 2 de la Ley 50 de 1936 permite al juez declarar de oficio aun sin petición de parte la nulidad absoluta cuando aparezca de manifiesto en el acto o contrato, se debe proceder a decretar la nulidad absoluta de la cláusula respectiva.

El efecto que tal declaración de nulidad produce en relación con la cláusula, es el de ponerle fin a la misma, de manera que esta desaparece del acuerdo contractual y deja en efecto la duración del contrato pactada originalmente, de forma tal que el contrato resultará incumplido de parte de quien con base en aquella cláusula pretenda retirarse de manera unilateral del contrato.

\section{Conclusiones}

Las principales conclusiones derivadas de lo expuesto en este artículo son:

- Según el principio de intangibilidad del contrato, reconocido en el Código Civil, este es ley para las partes y una vez perfeccionado está llamado a producir sus efectos y no termina sino por consentimiento mutuo o por causas legales, de lo cual surge que a los contratantes no les está permitido dar por terminado de manera unilateral el acuerdo contractual. No obstante, ya sea por pacto entre las partes o por expresa y excepcional facultad legal, los contratantes podrían ponerle fin al contrato de manera unilateral.

- Las cláusulas de terminación unilateral del contrato han sido admitidas en el Derecho Privado colombiano, tanto por la doctrina como por la jurisprudencia, incluyendo una serie de laudos arbitrales. De todas maneras, debe tenerse en cuenta que tales cláusulas encuentran límites en principios generales como el abuso del derecho y la buena fe, lo cual puede conllevar incluso que la cláusula sea calificada como abusiva, y por ende violatoria de normas imperativas, con la consecuente posible declaración de nulidad absoluta parcial de las mismas.

\section{Bibliografía}

\section{Libros}

ABELIUK-MANASEVICH, RENÉ, Las obligaciones, Tomo I (6a ed., Thomson Reuters, Santiago, 2014).

ALESSANDRI-RODRÍGUEZ, ARTURO; SOMARRIVA-UNDURRAGA, MANUEL \& VODANOVIC-

HAKLICKA, ANTONIO, Tratado de las obligaciones, vol. III, Modificación y extinción de las obligaciones ( $2^{a}$ ed., Editorial Jurídica de Chile, Santiago, reimpresión 2004).

ARRUBLA-PAUCAR, JAIME ALBERTO, Contratos mercantiles. Teoria general del negocio mercantil (13a edición, Pontificia Universidad Javeriana, Legis, Bogotá, 2012).

BARRIENTOS-GRANDÓN, JAVIER, dir., Código Civil (Thomson Reuters, Santiago, 2013).

BERNAL-FANDIÑO, MARIANA, El deber de coherencia en el Derecho colombiano de los contratos (Pontificia Universidad Javeriana, Bogotá, 2013).

BIANCA, C. MASSIMO, Diritto civile, 3, Il contratto (Seconda edizione, Giuffrè Editore, Milano, 2000).

CLARO-SOLAR, LUIS, Explicaciones de derecho civil chileno y comparado, tomo XI, De las obligaciones II (Imprenta Nascimento, Santiago, 1937).

CORDERO-LOBATO, ENCARNA; MARÍN-LÓPEZ, MANUEL JESÚS \& CARRASCO-PERERA, ÁNGEL, dir., Derecho de obligaciones y contratos en general: Lecciones de Derecho Civil ( $3^{a}$ ed, Tecnos, Madrid, 2017). 
CUBIDES-CAMACHO, JORGE, Obligaciones ( $8^{a}$ ed., Pontificia Universidad Javeriana, Editorial Ibáñez, Bogotá, 2017).

DÍEZ-PICAZO, LUIS, Fundamentos del Derecho Civil patrimonial, tomo II, Las relaciones obligatorias (6a ed., Thomson Civitas, Elcano, Madrid, 2008).

DÍEZ-PICAZO, LUIS \& GULLÓN, ANTONIO, Sistema de Derecho Civil, vol. II, tomo 1, El contrato en general. La relación obligatoria (10a ed., Tecnos, Madrid, 2012).

FRANZONI, MASSIMO, Degli effetti del contratto, volume I, Efficacia del contratto e recesso unilaterale, artt. 1372-1373, en Il Codice Civile, Commentario (PIERO SCHLESINGER, Giuffrè Editore, Milano, 1998).

HINESTROSA, FERNANDO, Tratado de las obligaciones II. De las fuentes de las obligaciones: el negocio jurídico, vol. II (Universidad Externado de Colombia, Bogotá, 2015).

JARAMILLO-JARAMILLO, CARLOS IGNACIO, La compraventa en el Derecho del consumo (Pontificia Universidad Javeriana, Editorial Ibáñez, Bogotá, 2015).

JEREZ-DELGADO, CARMEN, coord., Principios, definiciones y reglas de un Derecho Civil europeo: el Marco Común de Referencia (DCFR) (BOE, Madrid, 2015). Disponible en: https://www.boe.es/publicaciones/biblioteca_juridica/publicacion.php?id=PUB-PR-2015-38_PRINCIP IOS_DEFINICIONES_Y_REGLAS_DE_UN_DERECHO_CIVIL_EUROPEO_EL_MARCO_COM \%C3\%9AN_DE_REFERENCIA_(DCFR)\&tipo=L\&modo $=1$

LÓPEZ-SANTA MARÍA, JORGE \& ELORRIAGA DE BONIS, FABIÁN, Los contratos. Parte general (6a ed., Thomson Reuters, Santiago, 2017).

NARVÁEZ-GARCÍA, JOSÉ IGNACIO, Derecho mercantil colombiano. Obligaciones y contratos mercantiles (2a ed., Legis, Bogotá, 2002).

OSPINA-FERNÁNDEZ, GUILLERMO, Régimen general de las obligaciones (8ª ed., 4a reimp., Temis, Bogotá, 2016).

OSPINA-FERNÁNDEZ, GUILLERMO \& OSPINA-ACOSTA, EDUARDO, Teoría general del contrato y del negocio jurídico ( $7^{\mathrm{a}}$ ed., $4^{\mathrm{a}}$ reimp., Temis, Bogotá, 2016).

RENGIFO-GARCÍA, ERNESTO, Las facultades unilaterales en la contratación moderna (2a ed., Legis, Bogotá, 2017). RODRÍGUEZ-YONG, CAMILO ANDRÉS, Una aproximación a las cláusulas abusivas (Legis, Universidad del Rosario, Bogotá, 2013).

ROPPO, VINCENZO, Il contratto (2a edizione, Giuffrè Editore, Milano, 2011).

SANGIORGI, SALVATORE, Rapporti di durata e recesso ad nutum (Giuffrè Editore, Milano, 1965).

SERRANO-ALONSO, EDUARDO \& SERRANO-GÓMEZ, EDUARDO, Manual de Derecho de obligaciones y contratos, tomo 1, Teoria general de la obligación (Edisofer, Madrid, 2007).

TERRÉ, FRANÇOIS; SIMLER, PHILIPPE \& LEQUETTE, YVES, Droit Civil. Les obligations (10e éd., Dalloz, Paris, 2009).

\section{Colaboración en obras colectivas}

BALLESTEROS DE LOS RÍOS, MARÍA, La modificación y la extinción de la relación obligatoria, en Manual de Derecho Civil, obligaciones, 163-178 (RODRIGO BERCOVITZ RODRÍGUEZ-CANO, coord., Bercal, Madrid, 2011).

BORDA, ALEJANDRO, Extinción de los contratos, en Derecho Civil, Contratos, 245-261 (ALEJANDRO BORDA, dir., Thomson Reuters La Ley, Buenos Aires, 2016).

BOTERO-ARISTIZÁBAL, LUIS FELIPE, Apuntes sobre la terminación unilateral de los contratos en el derecho privado colombiano, en La terminación del contrato, 365-390 (JOSÉ ALBERTO GAITÁN-MARTÍNEZ \& FABRICIO MANTILLA-ESPINOSA, dirs., Universidad del Rosario, Bogotá, 2007).

CHERUBINI, MARIA CARLA, Art. 1373. Recesso unilaterale, en Commentario del codice civile, dei contratti in generale, artt. 1350-1386, 668-681 (ENRICO GABRIELLI, dir., EMANUELA NAVARRETTA \& ANDREA ORESTANO, a cura di, Utet Giuridica, Torino, 2011). 
CLARIZIA, RENATO, Gli effetti. Capitolo XVI. Il recesso, en Diritto Civile, volume III, Obbligazioni, Il contratto in generale, 599-604 (NICOLÒ LIPARI \& PIETRO RESCIGNO, dirs., ANDREA ZOPPINI, coord., Giuffrè Editore, Milano, 2009).

GAMBOA-MORALES, LUIS CARLOS, Extinción del contrato, en Derecho de las obligaciones: con propuestas de modernización, Tomo II, 357-399 (2a ed., MARCELA CASTRO DE CIFUENTES, coord., Universidad de los Andes, Temis, Bogotá, 2016).

HINESTROSA, FERNANDO, La terminación unilateral del contrato, en Responsabilidad civil, 429-462 (AÍDA KEMELMAJER DE CARLUCCI, dir., Rubinzal Culzoni, Buenos Aires, 2007).

PALAZÓN-GARRIDO, MARÍA LUISA, Cláusulas de vigencia, terminación y desistimiento en contratos de tracto sucesivo, en Cláusulas en los contratos internacionales. Redacción y análisis, 458-473 (SIXTO A. SÁNCHEZLORENZO, coord., Atelier, Barcelona, 2012).

SIRENA, PIETRO, I recessi unilaterali, en Trattato del Contratto, III, Effetti, 113-139 (VINCENZO ROPPO, dir., MARIA COSTANZA, a cura di, Giuffrè Editore, Milano, 2006).

VOGENAUER, STEFAN, Article 5.1.8 (Contractfor an Indefinite Period), en Commentary on the Unidroit Principles of International Commercial Contracts (PICC), 643-647 (2nd ed., STEFAN VOGENAUER, ed., Oxford University Press, Oxford, 2015).

\section{Revistas}

BERNAL-FANDIÑO, MARIANA, Ventas a distancia y su tratamiento en el nuevo Estatuto del Consumidor, 124 Vniversitas (Pontificia Universidad Javeriana), $43-61$ (2012). Disponible en: https://revistas.javeriana.edu.co/i ndex.php/vnijuri/article/view/14268

MOLINA-MORALES, RANFER, La terminación unilateral ad nutum, 10 Revista de Derecho Privado (Universidad Externado de Colombia), 124-158 (2006). Disponible en: https://revistas.uexternado.edu.co/index.php/derpr i/article/view/586/553

MOLINA-MORALES, RANFER, La terminación unilateral del contrato por incumplimiento, 17 Revista de Derecho Privado (Universidad Externado de Colombia), 77-105 (2009). Disponible en: https://revistas.uexternado.edu .co/index.php/derpri/article/view/411/391

NAVIA-ARROYO, FELIPE, La terminación unilateral del contrato de Derecho Privado, 14 Revista de Derecho Privado (Universidad Externado de Colombia), 35-67 (2008). Disponible en: https://revistas.uexternado.edu.co/index .php/derpri/article/view/549/520

PIZARRO-WILSON, CARLOS, ¿Puede el acreedor poner término unilateral al contrato?, 13 Revista Ius et Praxis, 1 , 11-28 (2007). Disponible en: http://www.revistaiepraxis.cl/index.php/iepraxis/article/view/437/318

SOLARTE-RODRÍGUEZ, ARTURO, La buena fe contractual y los deberes secundarios de conducta, 108 Vniversitas (Pontificia Universidad Javeriana), 282-315 (2004). Disponible en: https://revistas.javeriana.edu.co/index.php /vnijuri/article/view/14730

\section{Tratados internacionales}

Comisión de las Naciones Unidas para el Derecho Mercantil Internacional, CNUDMI-UNCITRAL, Convención de Naciones Unidas sobre los Contratos de Compraventa Internacional de Mercaderías, 11 de abril de 1980. Disponible en: https://www.uncitral.org/pdf/spanish/texts/sales/cisg/V1057000-CISG-s.pdf

Comisión Europea, Borrador de Marco Común de Referencia. Disponible en: http://ec.europa.eu/justice/policies/c ivil/docs/dcfr_outline_edition_en.pdf

Principios de Derecho Europeo de Contratos. Disponible en: http://campus.usal.es/ derinfo/Material/LegOblCon tr/PECL\%20I+II.pdf 


\section{Normativa internacional}

Argentina, Ley 26.994, Código Civil y Comercial de la Nación, Boletin Oficial, 8 de octubre de 2014. Disponible en: http://www.saij.gob.ar/docs-f/codigo/Codigo_Civil_y_Comercial_de_la_Nacion.pdf

Chile, Código Civil, Ley de 14 de diciembre de 1855. Disponible en: https://www.leychile.cl/Navegar? idNorma $=172986$

Colombia, Código Civil, Ley 84 de 1873, 2.867 Diario Oficial, 31 de mayo de 1873. Disponible en: http://www.sec retariasenado.gov.co/senado/basedoc/codigo_civil.html

Colombia, Decreto extraordinario 1 de 1990,39.127 Diario Oficial, 2 de enero de 1990.

Colombia, Ley 1480 de 2011, por medio de la cual se expide el Estatuto del Consumidor y se dictan otras disposiciones, 48.220 Diario Oficial, 12 de octubre de 2011. Disponible en: http://www.secretariasenado.gov.co/senado/bas edoc/ley_1480_2011.html

Francia, Código Civil, Ley del 21 de marzo de 1804. Disponible en: https://www.legifrance.gouv.fr/affichCode.do?c idTexte=LEGITEXT000006070721, https://www.legifrance.gouv.fr/content/download/1966/13751/.../Co de_41.pdf

Italia, Código Civil, Regio Decreto 262, 16 de marzo de 1942. Disponible en: https://www.altalex.com/documents/ codici-altalex/2015/01/02/codice-civile, http://www.wipo.int/wipolex/es/text.jsp?file_id=430550

International Institute for the Unification of Private Law, UNIDROIT, Principios de Unidroit sobre los Contratos Comerciales Internacionales. Disponible en: https://www.unidroit.org/instruments/commercial-contracts/uni droit-principles-2016, https://www.unidroit.org/unidroit-principles-2016/unidroit-principles-2016-overview /spanish-black-letter

\section{Jurisprudencia colombiana. Sentencias y laudos arbitrales}

Centro de Arbitraje y Conciliación de la Cámara de Comercio de Bogotá, Laudo Arbitral, 3PL Logistic Solutions Colombia S.A.S. contra VIRBAC Colombia Ltda., 2 de junio de 2016, Tribunal de arbitramento compuesto por Jorge Oviedo-Albán (árbitro único). Disponible en: https://bibliotecadigital.ccb.org.co/bitstream/handle/115 20/21204/3674_3PL_LOGISTICS_vs_VIRBAC_COLOMBIA_02_06_16.pdf? sequence $=1$ \&isAllowed $=\mathrm{y}$

Centro de Arbitraje y Conciliación de la Cámara de Comercio de Bogotá, Laudo arbitral, Adriana María CalderónPalacio vs. Cafesalud Medicina Prepagada S.A., 15 de noviembre de 2002, Tribunal de arbitramento compuesto por Francisco Morales-Casas (presidente), Sergio Muñoz-Laverde y Roberto Uribe-Ricaurte. Disponible en: https://bibliotecadigital.ccb.org.co/bitstream/handle/11520/21557/SN_111_Adriana_Maria_Calderon_ VS_Cafesalud_2002_11_15.pdf?sequence $=1 \&$ isAllowed $=\mathrm{y}$

Centro de Arbitraje y Conciliación de la Cámara de Comercio de Bogotá, Laudo arbitral, Autonal S.A. contra Sofasa S.A., 25 de abril de 2017, Tribunal de arbitramento compuesto por Sergio Muñoz-Laverde, Fernando Pabón y Guillermo Zea. Disponible en: https://bibliotecadigital.ccb.org.co/bitstream/handle/11520/21312/4011_AU TONAL_vs_SOFASA_25_04_17.pdf?sequence=1\&isAllowed=y

Centro de Arbitraje y Conciliación de la Cámara de Comercio de Bogotá, Laudo arbitral, Flor Alicia Triana Sandoval contra Conjunto Residencial Casas del Este P.H., 10 de noviembre de 2017, Tribunal de arbitramento compuesto por Jorge Sanmartín Jiménez (árbitro único). Disponible en: https://bibliotecadigital.ccb.org.co/bitstream/ handle/11520/21389/5202_FLOR_ALICIA_TRIANA_VS._CONJUNTO_RESIDENCIAL_CASAS_DEL_ESTE_ \%28Social\%29_10_11_2017.pdf?sequence=18isAllowed=y

Centro de Arbitraje y Conciliación de la Cámara de Comercio de Bogotá, Laudo arbitral, Punto Celular Ltda. contra Comunicación Celular S.A. - Comcel S.A., 23 de febrero de 2007, Tribunal de arbitramento compuesto por David Luna-Bisbal (presidente), Sergio Muñoz-Laverde y Pedro Nel Escorcia. Disponible en: https://bibliotecadigital.ccb.org.co/bitstream/handle/11520/21735/1225_V_PUNTO_CELULAR_LT DA_vs_COMCEL_23_02_07.pdf?sequence $=1 \&$ isAllowed $=\mathrm{y}$ 
Consejo de Estado, Sala de lo Contencioso Administrativo, Sección tercera, Subsección B, 2 de mayo de 2016, consejero ponente Ramiro Pazos-Guerrero, Radicación 11001-03-26-000-2014-00063-00 (51113.

Corte Suprema de Justicia, Sala de Casación Civil, 3 de septiembre de 1941, magistrado ponente Ricardo Hinestrosa-Daza, Gaceta Judicial, tomo LII, número 1977, 36-46 (1941). Disponible en: http://www.cortesuprema.gov.co/corte/wp-content/uploads/subpage/GJ/Gaceta\%20Judicial/GJ\%20LII \%20n.\%C2\%B0\%201977-1982\%20(1941-1942).pdf

Corte Suprema de Justicia, Sala de Casación Civil, 2 de febrero de 2001, magistrado ponente Carlos Ignacio JaramilloJaramillo, expediente 5670. Disponible en: http://www.cortesuprema.gov.co, http://hipertexto-obligaciones.u niandes.edu.co/lib/exe/fetch.php?media=sentencia_2_de_febrero_2001.doc

Corte Suprema de Justicia, Sala de Casación Civil, 14 de diciembre de 2001, magistrado ponente Carlos Ignacio Jaramillo-Jaramillo, expediente 6230. Disponible en: http://www.cortesuprema.gov.co, http://hipertexto-obli gaciones.uniandes.edu.co/lib/exe/fetch.php?media=sentencia_2_de_febrero_2001.doc

Corte Suprema de Justicia, Sala de Casación Civil, 30 de agosto de 2011, magistrado ponente William Namén-Vargas, ref. 11001-3103-012-1999-01957-01. Disponible en: http://www.cortesuprema.gov.co, https://corte-suprema -justicia.vlex.com.co/vid/-316765778

\section{Notas}

* Artículo de investigación

1 GUILLERMO OSPINA-FERNÁNDEZ \& EDUARDO OSPINA-ACOSTA, Teoría general del contrato y del negocio jurídico, 497 (7a ed., 4a reimp., Temis, Bogotá, 2016).

2 Acerca del principio que denominan "normatividad de los actos jurídicos", bajo el entendido de que no es exclusivo de los contratos sino también de ciertos actos unipersonales, y asumido como una delegación en la voluntad privada de la potestad ordenadora en principio correspondiente a la ley: GUILLERMO OSPINA-FERNÁNDEZ \& EDUARDO OSPINAACOSTA, Teoría general del contrato y del negocio jurídico, 306 ( $7^{\mathrm{a}}$ ed., 4a reimp., Temis, Bogotá, 2016). También FERNANDO HINESTROSA, Tratado de las obligaciones II. De las fuentes de las obligaciones: el negocio jurídico, vol. II, 946 (Universidad Externado de Colombia, Bogotá, 2015). De igual forma en la doctrina chilena, la fuerza obligatoria se concibe como un principio de los contratos que resulta como un subprincipio o corolario necesario del principio general de la autonomía de la voluntad: JORGE LÓPEZ-SANTA MARÍA \& FABIÁN ELORRIAGA DE BONIS, Los contratos. Parte general, 288 ( 6 a ed., Thomson Reuters, Santiago, 2017). Sobre el origen de esta norma, que en el caso chileno corresponde al artículo 1545 del Código Civil, su fuente en el artículo 1134 del Code francés y en las fuentes romanas: JAVIER BARRIENTOS-GRANDÓN, dir., Código Civil, 1280-1282 (Thomson Reuters, Santiago, 2013). También sobre el origen en la norma francesa y las fuentes romanas y el valor de ley reconocido al contrato: LUIS CLARO-SOLAR, Explicaciones de derecho civil chileno y comparado, tomo XI, De las obligaciones II, 469-470 (Imprenta Nascimento, Santiago, 1937).

3 GUILLERMO OSPINA-FERNÁNDEZ, Régimen general de las obligaciones, 314 (8a ed., $4^{\mathrm{a}}$ reimp., Temis, Bogotá, 2016). FERNANDO HINESTROSA, La terminación unilateral del contrato, en Responsabilidad civil, 429-462, 430 (AIIDA KEMELMAJER DE CARLUCCI, dir., Rubinzal Culzoni, Buenos Aires, 2007). RANFER MOLINA-MORALES, La terminación unilateral ad nutum, 10 Revista de Derecho Privado (Universidad Externado de Colombia), 124-158 (2006).

4 En este sentido, LUIS CLARO-SOLAR, Explicaciones de derecho civil chileno y comparado, tomo XI, De las obligaciones II, 490-491 (Imprenta Nascimento, Santiago, 1937).

5 FERNANDO HINESTROSA, Tratado de las obligaciones II. De las fuentes de las obligaciones: el negocio jurídico, vol. II, 433 (Universidad Externado de Colombia, Bogotá, 2015).

6 Para los efectos de este artículo no se incluyen las cláusulas de terminación unilateral ante el incumplimiento de cualquiera de los contratantes. Sobre este aspecto: FERNANDO HINESTROSA, La terminación unilateral del contrato, en Responsabilidad civil, 429-462, 441-444 (AÍDA KEMELMAJER DE CARLUCCI, dir., Rubinzal Culzoni, Buenos Aires, 2007). RANFER MOLINAMORALES, La terminación unilateral del contrato por incumplimiento, 17 Revista de Derecho Privado (Universidad Externado de Colombia), 77-105 (2009). En la doctrina chilena: CARLOS PIZARRO-WILSON, ¿Puede el acreedor poner término unilateral al contrato?, 13 Revista Ius et Praxis, 1, 11-28 (2007). 
7 Como sucede en los siguientes casos: artículo 1858 CC (retracto cuando se pactan solemnidades contractuales); artículo 1859 CC y 866 CCo (retracto en la venta con arras); artículo 1878 CC (desistimiento del contrato de compraventa de género); 1979 CC (arrepentimiento en el arrendamiento sometido a solemnidades convencionales); artículos 2009 y 2025 CC (desahucio en el contrato de arrendamiento); artículo 2066 CC (terminación unilateral en el arrendamiento de servicios inmateriales); numerales 3 y 4 artículo 2191 CC (revocación y renuncia en el contrato de mandato); artículo 977 CCo (terminación por cualquiera de las partes del contrato de suministro); artículo 1002 CCo (modificado por el art. 16 del Decreto Extraordinario 01 de 1990) (desistimiento del pasajero en el contrato de transporte); artículos 1071 y 1159 CCo (revocación en el contrato de seguro); artículo 1197 numeral 2 CCo (preaviso por cualquiera de las partes en el contrato de hospedaje); artículo 1261 numeral 4 CCo (denuncia en el contrato de cuenta corriente mercantil); artículo 1232 CCo (renuncia del fiduciario); artículo 1240 numeral 11 CCo (revocación del fiduciante); artículo 1270 CCo (revocación del mandante en el mandato mercantil); artículo 1283 CC (renuncia del mandatario en el mandato comercial); artículo 1324 CCo (terminación unilateral en el contrato de agencia comercial); artículo 1389 CCo (terminación por revocación de cualquiera de las partes en el contrato de cuenta corriente bancaria); artículo $1406 \mathrm{CCo}$ (terminación por cualquiera de las partes en el contrato de apertura de crédito); artículo 1411 CCo (revocación de la carta de crédito); artículo 1419 CCo (terminación unilateral en el contrato de cajillas de seguridad); artículo 1620 CCo (desistimiento del cargador en el contrato de transporte marítimo de cosas); artículo 1878 CCo (desistimiento del pasajero en transporte aéreo de personas). Sobre estos casos y la tipología que de ellos resulta: LUIS FELIPE BOTERO-ARISTIZÁBAL, Apuntes sobre la terminación unilateral de los contratos en el derecho privado colombiano, en La terminación del contrato, 365-390, 371-375 (JOSÉ ALBERTO GAITÁN-MARTÍNEZ \& FABRICIO MANTILLA-ESPINOSA, dirs., Universidad del Rosario, Bogotá, 2007). FELIPE NAVIA-ARROYO, La terminación unilateral del contrato de Derecho Privado, 14 Revista de Derecho Privado (Universidad Externado de Colombia), 35-67, 36-38 (2008). GUILLERMO OSPINA-FERNÁNDEZ, Régimen general de las obligaciones, 316 ( $8^{\mathrm{a}}$ ed., $4^{\mathrm{a}}$ reimp., Temis, Bogotá, 2016). FERNANDO HINESTROSA, La terminación unilateral del contrato, en Responsabilidad civil, 429-462, 432-434 (AÍDA KEMELMAJER DE CARLUCCI, dir., Rubinzal Culzoni, Buenos Aires, 2007). FERNANDO HINESTROSA, Tratado de las obligaciones II. De las fuentes de las obligaciones: el negocio jurídico, vol. II, 951 (Universidad Externado de Colombia, Bogotá, 2015). En sus comentarios, MARÍA LUISA PALAZÓN-GARRIDO destaca que los ordenamientos jurídicos — refiriéndose ella particularmente al Derecho francés y español— suelen contemplar excepciones al principio de obligatoriedad de los contratos, los cuales deben interpretarse de modo restrictivo. MARÍA LUISA PALAZÓN-GARRIDO, Cláusulas de vigencia, terminación y desistimiento en contratos de tracto sucesivo, en Cláusulas en los contratos internacionales. Redacción y análisis, 458-473, 462 (SIXTO A. SÁNCHEZ-LORENZO, coord., Atelier, Barcelona, 2012). En Francia: FRANÇOIS TERRÉ, PHILIPPE SIMLER \& YVES LEQUETTE, Droit Civil. Les obligations, 667-668 (10e éd., Dalloz, Paris, 2009). Y en la doctrina chilena: JORGE LÓPEZ-SANTA MARÍA \& FABIÁN ELORRIAGA DE BONIS, Los contratos. Parte general, 352 (6a ed., Thomson Reuters, Santiago, 2017).

8 Sobre el particular, la amplia explicación de CARLOS IGNACIO JARAMILLO-JARAMILLO, La compraventa en el Derecho del consumo, 295-384 (Pontificia Universidad Javeriana, Editorial Ibáñez, Bogotá, 2015). Por su parte, MARIANA BERNAL-FANDIÑO afirma que el retracto o desistimiento del que dispone el consumidor en el marco de la Ley 1480 de 2011 o Estatuto del Consumidor, no resulta ajeno a la estructura lógico-normativa existente. Cfr. MARIANA BERNAL-FANDIÑO, Ventas a distancia y su tratamiento en el nuevo Estatuto del Consumidor, 124 Vniversitas (Pontificia Universidad Javeriana), 43-61, $52(2012)$.

9 LUIS DÍEZ-PICAZO, Fundamentos del Derecho Civil patrimonial, tomo II, Las relaciones obligatorias, 1087 (6a ed., Thomson Civitas, Elcano, Madrid, 2008). También en la manualística española: MARÍA BALLESTEROS DE LOS RÍOS, La modificación y la extinción de la relación obligatoria, en Manual de Derecho Civil, obligaciones, 163-178, 176 (RODRIGO BERCOVITZ RODRÍGUEZ-CANO, coord., Bercal, Madrid, 2011). ENCARNA CORDERO-LOBATO, MANUEL JESÚS MARÍN-LÓPEZ \& ÁNGEL CARRASCO-PERERA, dir., Derecho de obligaciones y contratos en general: Lecciones de Derecho Civil, 303 (3 $3^{\mathrm{a}}$ ed, Tecnos, Madrid, 2017). LUIS DÍEZ-PICAZO \& ANTONIO GULLÓN, Sistema de Derecho Civil, vol. II, tomo 1, El contrato en general. La relación obligatoria, 252 (10 ed., Tecnos, Madrid, 2012). EDUARDO SERRANO-ALONSO \& EDUARDO SERRANO-GÓMEZ, Manual de Derecho de obligaciones y contratos, tomo 1, Teoria general de la obligación, 185 (Edisofer, Madrid, 2007).

10 Cfr. LUIS FELIPE BOTERO-ARISTIZÁBAL, Apuntes sobre la terminación unilateral de los contratos en el derecho privado colombiano, en La terminación del contrato, 365-390,384-385 (JOSÉ ALBERTO GAITÁN-MARTÍNEZ \& FABRICIO MANTILLA-ESPINOSA, dirs., Universidad del Rosario, Bogotá, 2007). Véase también: LUIS CARLOS GAMBOAMORALES, Extinción del contrato, en Derecho de las obligaciones: con propuestas de modernización, Tomo II, 357-399, 372 (2a ed., MARCELA CASTRO DE CIFUENTES, coord., Universidad de los Andes, Temis, Bogotá, 2016). JORGE CUBIDESCAMACHO, Obligaciones, 477 ( $8^{a}$ ed., Pontificia Universidad Javeriana, Editorial Ibáñez, Bogotá, 2017). GUILLERMO OSPINA-FERNÁNDEZ, Régimen general de las obligaciones, 314-315 (8a ed., 4a reimp., Temis, Bogotá, 2016). ERNESTO RENGIFO-GARCÍA, Las facultades unilaterales en la contratación moderna, 103-117 (2ª ed., Legis, Bogotá, 2017). 
11 RENÉ ABELIUK-MANASEVICH, Las obligaciones, Tomo I, 207 (6a ed., Thomson Reuters, Santiago, 2014). También ANTONIO VODANOVIC-HAKLICKA, en ARTURO ALESSANDRI-RODRÍGUEZ, MANUEL SOMARRIVAUNDURRAGA \& ANTONIO VODANOVIC-HAKLICKA, Tratado de las obligaciones, vol. III, Modificación y extinción de las obligaciones, 117-118 (2a ed., Editorial Jurídica de Chile, Santiago, reimpresión 2004). JORGE LÓPEZ-SANTA MARÍA \& FABIÁN ELORRIAGA DE BONIS, Los contratos. Parte general, 352 (6ª ed., Thomson Reuters, Santiago, 2017).

12 Esta constituyó una novedad frente al Código de 1865. Puede verse en general, entre otros: SALVATORE SANGIORGI, Rapporti di durata e recesso ad nutum (Giuffrè Editore, Milano, 1965). MASSIMO FRANZONI, Degli effetti del contratto, volume I, Efficacia del contratto e recesso unilaterale, artt. 1372-1373, en Il Codice Civile, Commentario, 308-385 (PIERO SCHLESINGER, Giuffrè Editore, Milano, 1998). PIETRO SIRENA, I recessi unilaterali, en Trattato del Contratto, III, Effetti, 113-139 (VINCENZO ROPPO, dir., MARIA COSTANZA, a cura di, Giuffrè Editore, Milano, 2006). RENATO CLARIZIA Gli effetti. Capitolo XVI. Il recesso, en Diritto Civile, volume III, Obbligazioni, Il contratto in generale, 599-604 (NICOLÒ LIPARI \& PIETRO RESCIGNO, dirs., ANDREA ZOPPINI, coord., Giuffrè Editore, Milano, 2009). MARIA CARLA CHERUBINI, Art. 1373. Recesso unilaterale, en Commentario del codice civile, dei contratti in generale, artt. 1350-1386, 668-681 (ENRICO GABRIELLI, dir., EMANUELA NAVARRETTA \& ANDREA ORESTANO, a cura di, Utet Giuridica, Torino, 2011). VINCENZO ROPPO, Il contratto, 513-516 (2ª edizione, Giuffrè Editore, Milano, 2011).

13 Cfr. C. MASSIMO BIANCA, Diritto civile, 3, Il contratto, 737 (Seconda edizione, Giuffrè Editore, Milano, 2000).

14 MASSIMO FRANZONI, Degli effetti del contratto, volume I, Efficacia del contratto e recesso unilaterale, artt. 1372-1373, en Il Codice Civile, Commentario, 320 (PIERO SCHLESINGER, Giuffrè Editore, Milano, 1998).

15 Tal norma dispone: "Artículo 1077. Extinción por declaración de una de las partes. El contrato puede ser extinguido total o parcialmente por la declaración de una de las partes, mediante rescisión unilateral, revocación o resolución, en los casos en que el mismo contrato, o la ley, le atribuyen esa facultad”. El código, sancionado por Ley 26994, está vigente desde el 1 de agosto de 2015. Cfr. el comentario a esta disposición en ALEJANDRO BORDA, Extinción de los contratos, en Derecho Civil, Contratos, 245-261, 249 (ALEJANDRO BORDA, dir., Thomson Reuters La Ley, Buenos Aires, 2016).

16 El texto de este artículo establece: "Cualquiera de las partes puede resolver un contrato de tiempo indefinido, notificándolo con razonable anticipación”. Comentarios a este artículo: STEFAN VOGENAUER, Article 5.1.8, (Contract for an Indefinite

Period), en Commentary on the Unidroit Principles of International Commercial Contracts (PICC), 643-647 (2 ${ }^{\text {nd }}$ ed., STEFAN VOGENAUER, ed., Oxford University Press, Oxford, 2015).

17 El texto del artículo 6:109 PECL establece: "Un contrato de duración indeterminada puede finalizar mediante notificación realizada por cualquiera de las partes con un preaviso razonable". El numeral 2 del artículo III-1:109 DCFR establece: "Cuando, en un caso que supone el cumplimiento continuo o periódico de una obligación contractual, los términos del contrato no establezcan cuándo se extinguirá la relación contractual o digan que no lo hará nunca, cualquiera de las partes podrá extinguirla previa notificación con una antelación razonable. Para evaluar si la notificación se ha realizado con una antelación razonable, deberá tenerse en cuenta el intervalo entre prestaciones o contraprestaciones”. La versión en español del DFCR consultada corresponde a CARMEN JEREZ-DELGADO, coord., Principios, definiciones y reglas de un Derecho Civil europeo: el Marco Común de Referencia (DCFR) (BOE, Madrid, 2015).

18 MARÍA LUISA PALAZÓN-GARRIDO, Cláusulas de vigencia, terminación y desistimiento en contratos de tracto sucesivo, en Cláusulas en los contratos internacionales. Redacción y análisis, 458-473, 473 (SIXTO A. SÁNCHEZ-LORENZO, coord., Atelier, Barcelona, 2012).

19 Corte Suprema de Justicia, Sala de Casación Civil, 3 de septiembre de 1941, magistrado ponente Ricardo Hinestrosa-Daza, Gaceta Judicial, tomo LII, número 1977, 36-46, 38 (1941). Disponible en: http://www.cortesuprema.gov.co/corte/wp-content/ uploads/subpage/GJ/Gaceta\%20Judicial/GJ\%20LII\%20n.\%C2\%B0\%201977-1982\%20(1941-1942).pdf

20 Corte Suprema de Justicia, Sala de Casación Civil, 3 de septiembre de 1941, magistrado ponente Ricardo Hinestrosa-Daza, Gaceta Judicial, tomo LII, número 1977, 36-46, 45 (1941).

21 Cfr. Corte Suprema de Justicia, Sala de Casación Civil, 14 de diciembre de 2001, magistrado ponente Carlos Ignacio Jaramillo-Jaramillo, expediente 6230. Disponible en: http://www.cortesuprema.gov.co, http://hipertexto-obligaciones.uniandes .edu.co/lib/exe/fetch.php?media=sentencia_2_de_febrero_2001.doc

22 Cfr. Corte Suprema de Justicia, Sala de Casación Civil, 30 de agosto de 2011, magistrado ponente William Namén-Vargas, ref. 11001-3103-012-1999-01957-01. Disponible en: http://www.cortesuprema.gov.co, https://corte-suprema-justicia.vlex.com .co/vid/-316765778 
23 Corte Suprema de Justicia, Sala de Casación Civil, 30 de agosto de 2011, magistrado ponente William Namén-Vargas, ref. 11001-3103-012-1999-01957-01.

24 Consejo de Estado, Sala de lo Contencioso Administrativo, Sección tercera, Subsección B, 2 de mayo de 2016, consejero ponente Ramiro Pazos-Guerrero, Radicación 11001-03-26-000-2014-00063-00 (51113).

25 Según nota incluida en el propio texto citado: "Los artículos 1870, 1878, 1882, 1983, 1984 y 2185 del Código Civil permiten que una parte haga cesar en sus efectos al contrato, por su mera manifestación de voluntad, y al margen de proceso judicial”. Hay que anotar que en este fallo hay una alusión que no resulta muy precisa a las reglas de la Convención de Naciones Unidas sobre los Contratos de Compraventa Internacional de Mercaderías y a los Principios de Unidroit sobre los Contratos Comerciales Internacionales. La mencionada decisión en sus consideraciones incluye las razones por las cuales considera viable pactar una cláusula de terminación unilateral en el contrato, para lo cual se apoya en doctrina y con referencia a la sentencia de 30 de agosto de 2011 de la Corte Suprema de Justicia ya citada, y entre ellas menciona la facultad reconocida tanto en la Convención (artículo 26) como en los Principios de Unidroit (artículo 7.3.1). Estas disposiciones - como bien lo recuerda también el fallo citado del Consejo de Estado - aluden a la facultad unilateral de ponerle fin al contrato por una de las partes en caso de incumplimiento de la otra. Como se ha venido indicando, y también a ello es a lo que se refiere el fallo en cita, la cláusula de terminación unilateral del contrato objeto de comentarios en este artículo, no prevé tal posibilidad ante el incumplimiento del contrato.

26 Centro de Arbitraje y Conciliación de la Cámara de Comercio de Bogotá, Laudo arbitral, Autonal S.A. contra Sofasa S.A., 25 de abril de 2017, Tribunal de arbitramento compuesto por Sergio Muñoz-Laverde, Fernando Pabón y Guillermo Zea. Disponible en: https://bibliotecadigital.ccb.org.co/bitstream/handle/11520/21312/4011_AUTONAL_vs_SOFASA_25_04_17.pdf?sequ ence $=1 \&$ isAllowed $=y$

27 Corte Suprema de Justicia, Sala de Casación Civil, 30 de agosto de 2011, magistrado ponente William Namén-Vargas, ref. 11001-3103-012-1999-01957-01.

28 Consejo de Estado, Sala de lo Contencioso Administrativo, Sección tercera, Subsección B, 2 de mayo de 2016, consejero ponente Ramiro Pazos-Guerrero, Radicación 11001-03-26-000-2014-00063-00 (51113).

29 ERNESTO RENGIFO-GARCÍA, Las facultades unilaterales en la contratación moderna, 113 (2a ed., Legis, Bogotá, 2017).

30 ERNESTO RENGIFO-GARCÍA, Las facultades unilaterales en la contratación moderna, 118 (2a ed., Legis, Bogotá, 2017). De igual forma, FERNANDO HINESTROSA, La terminación unilateral del contrato, en Responsabilidad civil, 429-462, 453 (AÍDA KEMELMAJER DE CARLUCCI, dir., Rubinzal Culzoni, Buenos Aires, 2007).

31 LUIS DÍEZ-PICAZO \& ANTONIO GULLÓN, Sistema de Derecho Civil, vol. II, tomo 1, El contrato en general. La relación obligatoria, 252 (10ª ed., Tecnos, Madrid, 2012). También en LUIS DÍEZ-PICAZO, Fundamentos del Derecho Civil patrimonial, tomo II, Las relaciones obligatorias, 1088 (6a ed., Thomson Civitas, Elcano, Madrid, 2008).

32 LUIS DÍEZ-PICAZO, Fundamentos del Derecho Civil patrimonial, tomo II, Las relaciones obligatorias, 1088 (6a ed., Thomson Civitas, Elcano, Madrid, 2008).

33 BIANCA, C. MASSIMO, Diritto civile, 3, Il contratto, 741 (Seconda edizione, Giuffrè Editore, Milano, 2000). También se ha dicho que el límite puede provenir de la naturaleza o la función económico-social del contrato. SALVATORE SANGIORGI, Rapporti di durata e recesso ad nutum, p., SALVATORE SANGIORGI, Rapporti di durata e recesso ad nutum, 174 (Giuffrè Editore, Milano, 1965).

34 ALEJANDRO BORDA, Extinción de los contratos, en Derecho Civil, Contratos, 245-261, 249 (ALEJANDRO BORDA, dir., Thomson Reuters La Ley, Buenos Aires, 2016).

35 FERNANDO HINESTROSA, La terminación unilateral del contrato, en Responsabilidad civil, 429-462, 453 (AÍDA KEMELMAJER DE CARLUCCI, dir., Rubinzal Culzoni, Buenos Aires, 2007). FERNANDO HINESTROSA, Tratado de las obligaciones II. De las fuentes de las obligaciones: el negocio jurídico, vol. II, 954 (Universidad Externado de Colombia, Bogotá, 2015).

36 BIANCA, C. MASSIMO, Diritto civile, 3, Il contratto, 741 (Seconda edizione, Giuffrè Editore, Milano, 2000). Igualmente, RENATO CLARIZIA Gli effetti. Capitolo XVI. Il recesso, en Diritto Civile, volume III, Obbligazioni, Il contratto in generale, 599-604, 603 (NICOLÒ LIPARI \& PIETRO RESCIGNO, dirs., ANDREA ZOPPINI, coord., Giuffrè Editore, Milano, 2009). 
37 FERNANDO HINESTROSA, La terminación unilateral del contrato, en Responsabilidad civil, 429-462, 459 (AÍDA KEMELMAJER DE CARLUCCI, dir., Rubinzal Culzoni, Buenos Aires, 2007). En Argentina, conforme al artículo 1078 (a) del Código Civil y Comercial de la Nación, que contempla una serie de disposiciones generales para la extinción del contrato por una de las partes, se exige que el derecho se ejerza mediante comunicación a la otra parte. En sentido de requerir el preaviso para la terminación unilateralmente del contrato con base en cláusula como la que es objeto de este trabajo, pueden verse también las consideraciones expuestas en algunos laudos arbitrales. Centro de Arbitraje y Conciliación de la Cámara de Comercio de Bogotá, Laudo arbitral, Autonal S.A. contra Sofasa S.A., 25 de abril de 2017, Tribunal de arbitramento compuesto por Sergio Muñoz-Laverde, Fernando Pabón y Guillermo Zea. Centro de Arbitraje y Conciliación de la Cámara de Comercio de Bogotá, Laudo arbitral, Flor Alicia Triana Sandoval contra Conjunto Residencial Casas del Este P.H., 10 de noviembre de 2017, Tribunal de arbitramento compuesto por Jorge Sanmartín Jiménez (árbitro único). Disponible en: https://bibliotecadigital.ccb.org.co/bitstream/handle/11520/21389/5202_FLOR_ALICIA_TRIANA_VS._CONJUNT O_RESIDENCIAL_CASAS_DEL_ESTE_\%28Social\%29_10_11_2017.pdf?sequence=1\&isAllowed=y

38 Cfr. ARTURO SOLARTE-RODRÍGUEZ, La buena fe contractual y los deberes secundarios de conducta, 108 Vniversitas (Pontificia Universidad Javeriana), 282-315, 288 (2004). Igualmente, MARIANA BERNAL-FANDINOO, El deber de coherencia en el Derecho colombiano de los contratos, 103 (Pontificia Universidad Javeriana, Bogotá, 2013). En relación con el deber de información derivado de la buena fe, resulta oportuno sobre este particular recordar las palabras de ARTURO SOLARTERODRÍGUEZ, quien sobre el particular expresa: "El deber de información tiene, por regla general, una manifestación positiva, entendida como ha quedado enunciada, pero también presenta una expresión negativa, consistente en el deber jurídico de abstenerse de engañar o de inducir a error al otro contratante. Se considera que quien tiene la información debe tomar la iniciativa para efectos de suministrarla a la otra parte de la relación e, incluso, debe indagar sus necesidades y su estado de conocimiento sobre el tema materia del respectivo contrato". ARTURO SOLARTE-RODRÍGUEZ, La buena fe contractual y los deberes secundarios de conducta, 108 Vniversitas (Pontificia Universidad Javeriana), 282-315, 307-308 (2004).

39 Corte Suprema de Justicia, Sala de Casación Civil, 2 de febrero de 2001, magistrado ponente Carlos Ignacio JaramilloJaramillo, expediente 5670. Disponible en: http://www.cortesuprema.gov.co, http://hipertexto-obligaciones.uniandes.edu.co/lib /exe/fetch.php?media=sentencia_2_de_febrero_2001.doc. El caso se refirió a una demanda en que se pidió declarar la existencia de un contrato de suministro entre las partes, la simulación relativa de un contrato de compraventa, el incumplimiento del mencionado contrato de suministro y su consecuente resolución, más las restituciones y pagos correspondientes. El juzgado de primera instancia declaró la existencia del contrato de suministro, reconoció que el pago del precio del mismo se hizo por la demandante mediante dación en pago realizada por escritura, aunque en ella se expresó que el negocio celebrado fue una compraventa, dispuso su resolución e impuso la obligación de restituir el pago del precio más los intereses de mora respectivos y costas. El fallo fue confirmado en apelación y la Corte no casó la sentencia.

40 Centro de Arbitraje y Conciliación de la Cámara de Comercio de Bogotá, Laudo arbitral, Adriana María Calderón-Palacio vs. Cafesalud Medicina Prepagada S.A., 15 de noviembre de 2002, Tribunal de arbitramento compuesto por Francisco MoralesCasas (presidente), Sergio Muñoz-Laverde y Roberto Uribe-Ricaurte. Disponible en: https://bibliotecadigital.ccb.org.co/bitstrea $\mathrm{m} /$ handle/11520/21557/SN_111_Adriana_Maria_Calderon_VS_Cafesalud_2002_11_15.pdf? sequence $=1 \&$ isAllowed $=y$

41 Centro de Arbitraje y Conciliación de la Cámara de Comercio de Bogotá, Laudo arbitral, Adriana María Calderón-Palacio vs. Cafesalud Medicina Prepagada S.A., 15 de noviembre de 2002, Tribunal de arbitramento compuesto por Francisco MoralesCasas (presidente), Sergio Muñoz-Laverde y Roberto Uribe-Ricaurte.

42 Centro de Arbitraje y Conciliación de la Cámara de Comercio de Bogotá, Laudo arbitral, Punto Celular Ltda. contra Comunicación Celular S.A. - Comcel S.A., 23 de febrero de 2007, Tribunal de arbitramento compuesto por David Luna-Bisbal (presidente), Sergio Muñoz-Laverde y Pedro Nel Escorcia. Disponible en: https://bibliotecadigital.ccb.org.co/bitstream/handle/ 11520/21735/1225_V_PUNTO_CELULAR_LTDA_vs_COMCEL_23_02_07.pdf?sequence=1\&isAllowed=y

43 Centro de Arbitraje y Conciliación de la Cámara de Comercio de Bogotá, Laudo arbitral, Punto Celular Ltda. contra Comunicación Celular S.A. - Comcel S.A., 23 de febrero de 2007, Tribunal de arbitramento compuesto por David Luna-Bisbal (presidente), Sergio Muñoz-Laverde y Pedro Nel Escorcia.

44 Centro de Arbitraje y Conciliación de la Cámara de Comercio de Bogotá, Laudo arbitral, Autonal S.A. contra Sofasa S.A., 25 de abril de 2017, Tribunal de arbitramento compuesto por Sergio Muñoz-Laverde, Fernando Pabón y Guillermo Zea.

45 Centro de Arbitraje y Conciliación de la Cámara de Comercio de Bogotá, Laudo Arbitral, 3PL Logistic Solutions Colombia S.A.S. contra VIRBAC Colombia Ltda., 2 de junio de 2016, Tribunal de arbitramento compuesto por Jorge Oviedo-Albán (árbitro único).Disponible en: https://bibliotecadigital.ccb.org.co/bitstream/handle/11520/21204/3674_3PL_LOGISTICS_vs_VIRB AC_COLOMBIA_02_06_16.pdf?sequence=18isAllowed $=y$ 
46 Como se recordará, los requisitos generales de validez de los contratos están contenidos en el artículo 1502 del Código Civil, a cuyo tenor: "Para que una persona se obligue a otra por un acto o declaración de voluntad, es necesario: 1. que sea legalmente capaz, 2. que consienta en dicho acto o declaración y su consentimiento no adolezca de vicio, 3. que recaiga sobre un objeto lícito, 4. que tenga una causa lícita. La capacidad legal de una persona consiste en poderse obligar por sí misma, sin el ministerio o la autorización de otra”. La inobservancia de tales requisitos da lugar a la nulidad del contrato, conforme a lo establecido en el artículo 1740 del Código Civil. Además, como también esta norma lo establece, la nulidad puede ser absoluta o relativa. También y según lo establecido en el artículo 1741 del Código Civil, la nulidad absoluta es la que se produce por un objeto o causa ilícita, por la omisión de algún requisito o formalidad que las leyes prescriben para el valor de ciertos actos o contratos en consideración a la naturaleza de ellos, o cuando se trata de actos y contratos celebrados por personas absolutamente incapaces. Por el contrario, los contratos celebrados por quienes no tengan la calidad de incapaces absolutos, los celebrados omitiendo algún requisito o formalidad que las leyes prescriben para el valor de ciertos actos o contratos atendiendo a la calidad o estado de las partes o cuando se trate de consentimiento viciado por error, fuerza o dolo, se genera nulidad relativa del contrato, conforme también lo establece el artículo 1741 del Código Civil. De igual forma, el Código de Comercio establece en el artículo 899 como causales de nulidad absoluta cuando el contrato contraría una norma imperativa, salvo que la ley establezca otra cosa; cuando tenga causa u objeto ilícitos y cuando se haya celebrado por persona absolutamente incapaz. Por su parte, el artículo 900 del Código de Comercio establece que el negocio jurídico será anulable cuando se haya celebrado por persona relativamente incapaz y cuando se haya consentido por error, fuerza o dolo, conforme al Código Civil. Cabe recordar que en el Código Civil, la terminología empleada por el artículo 1741 es nulidad absoluta y nulidad relativa, mientras los artículos 899 y 900 del Código de Comercio se refieren a la nulidad absoluta y la anulabilidad. Cfr. JAIME ALBERTO ARRUBLA-PAUCAR, Contratos mercantiles. Teoría general del negocio mercantil, 276 (13ª edición, Pontificia Universidad Javeriana, Legis, Bogotá, 2012). Como bien anotan OSPINA-FERNÁNDEZ Y OSPINAACOSTA: "El artículo 900 del Código de Comercio no introduce modificación en cuanto al concepto de lo que entiende por anulación del acto y que en el Código Civil se denomina nulidad relativa; esta continúa siendo la causada por la incapacidad relativa de los agentes y por vicios de la voluntad". GUILLERMO OSPINA-FERNÁNDEZ \& EDUARDO OSPINA-ACOSTA, Teoría general del contrato y del negocio jurídico, 484 ( $7^{\mathrm{a}}$ ed., $4^{\mathrm{a}}$ reimp., Temis, Bogotá, 2016).

47 Centro de Arbitraje y Conciliación de la Cámara de Comercio de Bogotá, Laudo arbitral, Punto Celular Ltda. contra Comunicación Celular S.A. - Comcel S.A., 23 de febrero de 2007, Tribunal de arbitramento compuesto por David Luna-Bisbal (presidente), Sergio Muñoz-Laverde y Pedro Nel Escorcia. Así, el tribunal sostuvo: "Dentro de la clasificación que divide a las normas en imperativas, dispositivas y supletivas, las disposiciones constitucionales son las que con mayor nitidez ostentan el primer carácter mencionado. Por eso, una cláusula abusiva, por el solo hecho de serlo e independientemente de su contenido material, debe considerarse contraria a la norma imperativa contenida en el citado artículo 95 de la Carta. De esa manera, y para los actos o contratos regidos por la ley comercial (23), se configura la causal de nulidad absoluta prevista en el ordinal 1 del artículo 899 del Código de Comercio que dispone: \#Será nulo absolutamente el negocio jurídico en los siguientes casos: 1 . Cuando contraría una norma imperativa, salvo que la ley disponga otra cosa\#. Para el tribunal es indudable, por la razón explicada, que una cláusula abusiva contraría la norma imperativa contenida en el artículo 95 de la Constitución Nacional, así su contenido material, individualmente considerado, no evidencie trasgresión de la ley, el orden público o las buenas costumbres”. En la doctrina, también RODRÍGUEZ-YONG refiere que esta es la posición mayoritaria en la jurisprudencia. CAMILO ANDRÉS RODRÍGUEZYONG, Una aproximación a las cláusulas abusivas, 69 (Legis, Universidad del Rosario, Bogotá, 2013).

48 Centro de Arbitraje y Conciliación de la Cámara de Comercio de Bogotá, Laudo Arbitral, 3PL Logistic Solutions Colombia S.A.S. contra VIRBAC Colombia Ltda., 2 de junio de 2016, Tribunal de arbitramento compuesto por Jorge Oviedo-Albán (árbitro único).

49 El texto de la norma es el siguiente: "Los principios que gobiernan la formación de los actos y contratos y las obligaciones de derecho civil, sus efectos, interpretación, modo de extinguirse, anularse o rescindirse, serán aplicables a las obligaciones y negocios jurídicos mercantiles, a menos que la ley establezca otra cosa”. En relación con los casos en que el Código de Comercio hace llamados directos a las reglas civiles y en las que las referencias son subsidiarias: JOSÉ IGNACIO NARVÁEZ-GARCÍA, Derecho mercantil colombiano. Obligaciones y contratos mercantiles, 202-204 (2a ed., Legis, Bogotá, 2002). Además, cabe recordar con Arrubla-PAUCAR, que “...por expresa disposición del legislador, contenida en el comentado artículo 822, las normas civiles relativas a este campo también son mercantiles”.JAIME ALBERTO ARRUBLA-PAUCAR, Contratos mercantiles. Teoría general del negocio mercantil, 30 (13ª edición, Pontificia Universidad Javeriana, Legis, Bogotá, 2012).

50 En este mismo sentido en la doctrina: JAIME ALBERTO ARRUBLA-PAUCAR, Contratos mercantiles. Teoría general del negocio mercantil, 279 (13 a edición, Pontificia Universidad Javeriana, Legis, Bogotá, 2012).

51 Cfr. CAMILO ANDRÉS RODRÍGUEZ-YONG, Una aproximación a las cláusulas abusivas, 71 (Legis, Universidad del Rosario, Bogotá, 2013) y los siguientes laudos arbitrales: Centro de Arbitraje y Conciliación de la Cámara de Comercio de Bogotá, Laudo arbitral, Punto Celular Ltda. contra Comunicación Celular S.A. - Comcel S.A., 23 de febrero de 2007, Tribunal de 
arbitramento compuesto por David Luna-Bisbal (presidente), Sergio Muñoz-Laverde y Pedro Nel Escorcia. Centro de Arbitraje y Conciliación de la Cámara de Comercio de Bogotá, Laudo Arbitral, 3PL Logistic Solutions Colombia S.A.S. contra VIRBAC Colombia Ltda., 2 de junio de 2016, Tribunal de arbitramento compuesto por Jorge Oviedo-Albán (árbitro único).

Licencia Creative Commons CC BY 4.0

Para citar este artículo / To cite this article: OVIEDO-ALBÁN,JORGE, La cláusula de terminación unilateral del contrato, 138 Vniversitas (2019). https://doi.org/10.11144/Javeriana.vj138.ctuc 